\title{
O MOBILE-LEARNING COMO SUPORTE PEDAGÓGICO PARA A FORMAÇÃO CONTINUADA DE PROFESSORES UNIVERSITÁRIOS - 0 DESENHO DE UM PLANEJAMENTO
}

\author{
CURITIBA/PR JUNHO/2018 \\ Joice Martins Diaz - UNINTER - joice.diaz@hotmail.com \\ Marilene Santana dos Santos Garcia - UNINTER - marilenegarc@uol.com.br \\ Tipo: Investigação Científica (IC) \\ Natureza: Planejamento de Pesquisa \\ Categoria: Métodos e Tecnologias \\ Setor Educacional: EDUCAÇÃO SUPERIOR
}

\begin{abstract}
RESUMO
O presente trabalho apresenta o desenho de um planejamento, a partir de suporte de pesquisa científica de uma dissertação de mestrado profissional, visando à construção de ações formação continuada de professores universitários em prática. Seu diferencial está no uso de dispositivos móveis, do aplicativo Whatsapp e de inovações na forma de conceber conteúdos e atividades. Com o domínio dos smartphones e de tecnologias móveis em todos os âmbitos, justifica-se pensar e planejar uma formação continuada para docentes universitários utilizando plataformas móveis, sinalizando para um projeto pedagógico inovador. O desenho deste planejamento implica as seguintes fases: i) desenvolvimento e aplicação de questionários, acerca do uso do Mobile Learning por professores de pedagogia de uma IES, para levantar as diferentes fluências digitais desse público-alvo, como também levanar quais necessidades de atualização desses professores; ii) pesquisa bibliográfica abarcando estudos de experiências já consolidadas sobre como os dispositivos móveis são aplicados na formação continuada de professores universitários; iii) desenvolvimento e implementação de atividades baseadas nos dados coletados nas etapas inicias; iv) aplicação de mais um questionário para fins de investigação, no sentido de obter informações sobre a relevância da metodologia e do conteúdo disponibilizado, sua aplicabilidade e utilidade em prática. O suporte teórico do presente artigo baseia-se em Moura (2014); Kenski (2015); Tardif (2014); Garcia (2017), entre outros.
\end{abstract}

Palavras-chave: mobile-learning, formação continuada, professores universitários. 


\section{Introdução}

É conhecida a necessidade constante da atualização de conteúdo, políticas e metodologias na formação continuada dos professores universitários. Partindo do princípio de que a Educação Contemporânea pode dispor das mais variadas tecnologias e que, quando bem utilizadas, podem facilitar a comunicação didática entre o professor e aluno, bem como na elaboração de materiais e recursos mediadores da aprendizagem, é necessário que o professor esteja constantemente integrando-se aos novos sistemas de trabalho e aprendizagens para exercer e investir em sua profissão. Além disso, devido ao frequente uso do smartphone pelos alunos, é importante pensar uma forma de aliar este uso a mecanismos pedagógicos para obter conhecimento real e significativo, bem saber como trabalhar a aprendizagem em ambientes presenciais e híbridos. Tais condições sinalizam para uma preparação imediata e segura dos professores sobre o uso desses recursos e plataformas.

Assim, o WhatsApp pode ser utilizado como ferramenta para proporcionar esta preparação, partindo do princípio de que é do uso constante deste público que o torna de fácil acesso e manuseio. Dessa maneira, o desenho desse planejamento de ações para atualização de professores parte dos seguintes questionamentos: o uso informal do Whatsapp permitiria também abrir um espaço para o uso educacional? A atenção e seu oposto, a dispersão e a desatenção, convivem, simultaneamente, pela interação com multitelas, partindo do princípio de que boa parte do que é recebido não se trata de conteúdo de aprendizado. Discute-se também até que ponto esta plataforma tão pessoal conseguiria prover informação, comunicação e aprendizado de forma eficaz. Outro questionamento relaciona-se com os próprios limites presentes nesse aplicativo e se estes poderiam interferir negativamente neste processo de formação de professores de nível superior em prática. Frente a esse contexto seria relevante oferecer uma formação continuada por meio de cursos de capacitações pontuais aos docentes universitários, para orientá-los na utilização das metodologias ativas na sala de aula e tendo como ferramenta pedagógica de apoio, o uso das tecnologias móveis.

\section{Referencial teórico}

Para o referencial teórico foram selecionadas algumas temáticas que se mesclam para dar suporte ao objetivo desse estudo, portanto, são relacionados aspectos sobre mobilelearning, o aplicativo Whatsapp; formação de professores de modo geral e aquele realizada com plataformas móveis.

\subsection{Dispositivo móvel}


Os dispositivos móveis são aparelhos, que como o próprio nome já antecipa, produzem mobilidade nas comunicações e de todas as demais ações que dela decorrem por programa específicos e pela conectividade.

Segundo Jubileu, Rocha e Ferreira (2012, p.2),

Um dispositivo móvel, designado popularmente em inglês por handheld é um computador de bolso habitualmente equipado com um pequeno ecrã (output) e um teclado em miniatura (input). Em alguns aparelhos, o output e o input combinam-se num ecrã táctil (touchscreen). Os dispositivos móveis mais comuns são: Smartphone; - PDA (Personal digital assistant); - Celular; - Console portatil; - Televisão portatil; - Aparelhos GPS (Sistema de posicionamento global). E computadores móveis: Notebooks e Tablets PCs.

Para os autores, as principais características dos dispositivos móveis são: móveis e portáteis, proporciona entretenimento, é multitarefas e facilita a comunicação. Serve para uso pessoal e profissional. (JUBILEU, ROCHA E FERREIRA, 2012). Devido ao seu grande uso por todas as faixas sociais e etárias, os dispositivos móveis impõem novos hábitos sociais, do trabalho e relacionados ao estudos. Trata-se de uma plataforma pessoal, personalizada, que contempla co-criação, edição, produção de informação, compartilhamento, comunicação síncrona e assíncrona, entre outros aspectos.

\subsection{Mobile-learning}

Mobile-learning originou-se já no final da década de 60, quando Alan Kay criou o conceito de Dynabook. Alan Kay, com a intenção de criar um computador para crianças de todas as idades, conduziu-se ao desenvolvimento de um protótipo do Xerox Alto, cujo nome original era o "Dinabook provisório" (SOUZA, 2013, p. 249).

O conceito mobile-learning representa integração das tecnologias móveis no contexto educativo, a qual permite que alunos e professores criem novos cenários de aprendizagem a distância. Para tanto, é necessário o uso de dispositivos móveis com acesso ou não à Internet. Pode-se trabalhar aplicativos para dispositivos móveis tanto online quanto off-line.

Para Garcia (2017, p. 83):

os conceitos de e-learning, m-learning e u-learning pertencem a mesma categoria das formas de aprendizagens mediadas por tecnologias digitais, pois trazem em si o termo "learning", o qual se relaciona com ações e ambientes de aprendizagem/ aplicativos/ produtos digitais com foco educacional.

As metodologias mais comuns do mobile-learning são: videoaulas, aplicativos, gamificação, livros digitais, cursos e-larning, redes sociais acadêmicas, dentre outros. Segundo Moura "com a evolução das tecnologias móveis têm vindo a desenvolver-se diversos projetos e atividades relacionados com o mobile-learning. A evolução deste 
conceito tem acompanhado o desenvolvimento das próprias tecnologias móveis" (MOURA, 2014, p. 2).

O mobile-learning, por se apropriar de smartphones e tablet, apresenta diversos benefícios como: mobilidade, rápido acesso a informação, autodidatismo, entretenimento, entre outros. Afirma Garcia que "o mobile-learning (m-learning) enfatiza a aprendizagem em contextos de mobilidade, contrapondo-se a acessos fechados e presentes em bases fixas de desktop conectadas a internet" (GARCIA, 2017, p.85).

Devido a esta e outras facilidades, o mobile-learning se torna cada vez mais atrativo. Apresenta-se a seguir, com base em Oliveira (2014), algumas vantagens referentes à aplicação em contexto educacional do Mobile-Learning, conforme mostra o quadro 1.

QUADRO 1 - Vantagens do uso de mobile-learning

\begin{tabular}{|l|l|}
\hline VANTAGENS & DESCRIÇÃO \\
\hline Autonomia & $\begin{array}{l}\text { Representa a liberdade para que o estudante organize } \\
\text { seu próprio estudo, utilizando, inclusive, a Internet para } \\
\text { buscar outras visões sobre determinado assunto e não } \\
\text { apenas as que são transmitidas pelo professor. }\end{array}$ \\
\hline Portabilidade/Mobilidade & $\begin{array}{l}\text { O estudante não precisa estar em espaços formais de } \\
\text { educação, como a sala de aula, por exemplo, para } \\
\text { aprender. Desse modo, professores e alunos podem } \\
\text { enviar e receber informações em qualquer local. }\end{array}$ \\
\hline $\begin{array}{l}\text { Facilidade de } \\
\text { entendimento }\end{array}$ & $\begin{array}{l}\text { O aluno pode estudar em seu Ambiente } \\
\text { Virtual de Aprendizagem preferido, dessa forma, há maior } \\
\text { comodidade para interação com os demais alunos e com } \\
\text { o professor }\end{array}$ \\
\hline Flexibilidade & $\begin{array}{l}\text { Possibilita que professores tenham maior aproximação } \\
\text { dos alunos, interagindo ou monitorando as atividades. }\end{array}$ \\
\hline \multicolumn{1}{|c|}{ Fonte: Baseada em } & Oliveira (2014. P. 3)
\end{tabular}

\subsection{Aplicativo de comunicação Whatsapp}

Segundo Oliveira et al. (2014) o Whatsapp[1], aplicativo multiplataforma, oferece vários benefícios como trocar mensagens de forma gratuita, compartilhar vídeos, imagens e enviar mensagens de voz. Além de todo conteúdo poder passar por um backup, é possível compartilhar a localização e criar grupos com até 50 participantes.

Este aplicativo não necessita de senhas e nome de usuários, pois funciona por meio do número de telefone celular cadastrado e se integra automaticamente com os números registrados na agenda do usuário. Outra vantagem que o aplicativo oferece é o de salvar e recuperar mensagens que não foram transmitidas enquanto o dispositivo móvel estava desligado ou fora de rede. As mensagens são enviadas automaticamente quando o usuário passa a ter acesso a rede ou o dispositivo é ligado novamente. 


\section{Formação inicial e continuada de professores}

Para Gatti (2010), a formação de professores se deu com a criação da Escola normais, no final do século XIX, para o ensino das "primeiras letras", que correspondiam ao nível secundário e, após, em meados do século XX, ao ensino médio. Até então este trabalho era exercido por profissionais liberais ou autodidatas, considerando o número pequeno de alunos e de escolas secundárias.

A formação inicial dos docentes, na maioria das vezes, se dá por meio dos cursos de licenciatura em pedagogia ou áreas específicas. É conhecido que muitos professores universitários iniciam sua carreira docente na educação básica. Sendo assim, é de extrema importância que os cursos de licenciaturas preparem este professor, no sentido de que proporcione aprendizagem significativas.

Para tanto, não basta a formação docente somente. É necessário que o professor esteja pronto para encarar novos desafios, estando disposto a aprender além da sua formação inicial. Diante disso, é relevante pensar em formação continuada constante, não só no sentido de aprimoramento de conteúdo, mas também de novas técnicas e tendências.

[1] Em 2016, segundo pesquisa divulgada pela Exame, o Whatsapp foi apontado como o aplicativo mais usado no Brasil, sendo um dos países que mais utilizam o aplicativo, perdendo apenas para Africa do Sul. Estimou-se que 76\% dos assinantes móveis, utilizam o aplicativo

Segundo Garcia (2017, p. 32)

a questão de formação continuada de professores torna-se, nesse sentido, pertinente e urgente, na medida em que, em sala de aula, o professor interage com alunos que demonstram habilidades e competências tecnológicas, imersivas e comunicativas, com alta fluência digital, advindas muitas vezes de aprendizagens não formais, ou seja, aquelas não institucionalizadas, realizadas a todo momento e a distância

Para Kenski "a cultura contemporânea está ligada à ideia de interconexão e de interrelação entre as pessoas, e delas com os mais diversos espaços virtuais de produção e disponibilização de informação" (KENSKI, 2015, p.7).

Partindo deste cenário atual, é de extrema importância que o professor esteja sempre buscando maneiras inovadoras de atuação em sala de aula, não só como forma de estar atualizado, mas também obtendo a atenção do aluno por meio da utilização de ferramentas interessantes e já presentes no seu cotidiano.

\subsection{Mobile-learning como ferramenta pedagógica na formação continuada}


A atuação do professor em sala de aula, após a chegada da internet, passou por consideráveis mudanças, pois o professor conta com práticas mediadas pelas tecnologias, como por exemplo computadores, sites, blogs, e-mail etc.

Os dispositivos móveis também influenciaram muito na prática docente. Segundo Garcia:

\footnotetext{
No momento em que as plataformas tecnológicas tornaram-se pessoais e personalizadas com a emergência dos dispositivos móveis, pode-se constatar mais um ponto de virada nas atividades docentes. Dessa vez os alunos começaram a protagonizar e dar direcionamento as práticas didáticas, tornando-se mais ativos, com mais senso crítico e sendo participativos nas escolhas sobre o que, onde, quando e por que estudar, ou mesmo fortalecendo suas próprias características de liderança, na condução de projetos. Sem dúvida, isso institui a ressignificação de propósitos educacionais e os meios para atingi-los (GARCIA, 2017, p. 232).
}

Frente a esta questão, é importante refletir sobre a formação continuada dos professores, com a intenção de preparar ou aperfeiçoar as práticas docentes mediadas pelo uso das tecnologias, tanto em ambientes presenciais quanto híbridos. Acredita-se que a formação continuada docente com foco no uso das tecnologias móveis como ferramenta pedagógica tornara-se cada vez mais frequente. Assim, Kenski afirma que:

\footnotetext{
A previsão para os próximos anos é que o acesso à internet será feito de forma muito mais intensa por meio de celulares e tablets do que pelos caminhos "naturais" e conhecidos dos PCs e da própria web. Ciclos cada vez mais acelerados ocorrem nos processos de criação, industrialização, consumo e superação das tecnologias digitais contemporâneas. E nos acostumamos a esse movimento. Em muitos casos, nem mais o percebemos porque a velocidade já se incorporou - como valor - ao nosso ritmo de vida (KENSKI, 2015, p.430).
}

Para complementar esta ideia, Silva e Batista ressaltam a importância da educação a distância em ambientes online, digitais e interativos que "consiste em romper com as distâncias espaços temporais e viabilizar recursos, interferências, conexões e trajetórias que permitem a disseminação de informações e tarefas" (SILVA E BATISTA, 2014, p.2936)

É evidente que se faz necessário um olhar diferenciado com relação a formação continuada dos docentes universitários atuantes nos dias de hoje, pois são eles que formam os novos professores que irão atuar em todos os níveis, garantindo então uma geração mais apta ao uso das tecnologias disponíveis.

\section{Proposta de planejamento - procedimentos metodológicos}

Pretende-se aplicar as seguintes metodologias: pesquisa exploratória como estudo preliminar do objetivo da pesquisa, pesquisa bibliográfica, com o objetivo de obter informações e dados que contribuirá na averiguação da proposta, desenho e aplicação 
do curso, aplicação de questionários por meio do método survey para coletas iniciais e finais de dados para análise da pesquisa, indicado nos casos que se tem por objetivo a obtenção de informações de um determinado público alvo, avaliação dos resultados obtidos a partir da oferta do curso e análise de conteúdo juntamente com os demais estudos para confirmação ou não das hipóteses

\subsection{Fases do planejamento}

O planejamento do referido curso de formação continuada de professores universitários será organizado a partir das fases:

- desenvolvimento e aplicação de questionários, acerca do uso do Mobile Learning em sala de aula pelos professores do curso de pedagogia de uma IES, para levantar as diferentes fluências digitais para o referido público-alvo;

- pesquisa bibliográfica abarcando estudos de experiências já consolidadas sobre como os dispositivos móveis são aplicados na formação continuada de professores universitários;

- desenvolvimento e implementação de atividades baseado nos dados coletados nas etapas inicias;

- aplicação de mais um questionário para fins de investigação, no sentido de obter informações sobre a relevância da metodologia e do conteúdo disponibilizado, sua aplicabilidade e utilidade em prática;

- Planejamento do conteúdo

O planejamento do conteúdo deverá acontecer a partir dos resultados das etapas, apontadas nas fases do planejamento (item 4.1), mas também deverão elaborar ações mais inovadoras no sentido de retrabalhar as sugestões dos professores com suportes e ideias mais inovadoras.

Assim, este processo relativo aos conteúdo da referida formação poderá abranger os seguintes tópicos:

a) Curadoria de textos e referências bibliográficas acerca dos assuntos mais apontados pelos professores nos questionários;

b) Envolvimento em atividades colaborativas e troca de experiências como suporte da inteligência coletiva a ser incentivada na abordagem pedagógica do curso;

c) Ênfase na Prática direta com seus alunos em sala de aula dos assuntos tratados no curso, de forma a abranger cotidiano na sala de aula sob uma perspectiva crítica e renovada;

d) Promover inovação nos ações didático-pedagógica, abrangendo redes de 
comunicação, bem como outros aplicativos de suporte além do Whatsapp.

\section{Objetivos}

\subsection{Objetivos gerais}

Como objetivos gerais espera-se compreender ações e atividades que possam apoiar a atualização de docentes, utilizando e ampliando soluções já conhecidas pelos usuários, como o uso do aplicativo Whatsapp, apoiando práticas

Como objetivos especificos, espera-se:

- Compreender o que é e a aplicabilidade do mobile-learning na formação continuada de professores universitários e seus benefícios;

- Revisar teoricamente sobre a formação continuada de professores com a utilização do Mobile-Learning; e seus benefícios;

- Criar uma metodologia para a formação continuada de professores do Ensino Superior, que atuam no nível de graduação, por meio do Mobile-Learning.

\section{Considerações finais}

A partir de um contexto repleto de novas tecnologias, utilizadas massivamente, torna-se preponderante pensar também de forma inovadora na preparação e formação continuada dos professores que atuam com os principais protagonistas de toda essa história, seus alunos,. Não se pensa mais no aluno como antigamente, que tinha o professor como o único detentor do saber e transmissor do conhecimento. Assim como, não podemos esquecer que o professor é e será continuamente um aluno, no sentido de sempre estar aprendendo para que possa ensinar de forma significativa.

Partindo desse pressuposto, o professor pode e deve contar com essas inovações e metodologias de forma que possa viabilizar e facilitar sua formação continuada, aprender ou aperfeiçoar a utilização das tecnologias móveis em seu cotidiano docente, tornando suas aulas mais atrativas e dentro de um contexto atual.

Como hipóteses desse estudo partimos das seguintes indagações: o curso desenvolvido consegue criar novas competências ao professor em termos de uso do smartphones e os docentes compreendem que o uso do mobile-learning trata-se de uma estratégia educacional satisfatória.

Acredita-se que com o desenvolvimento do presente projeto, possamos oferecer um 
reforço na atuação significativa dos professores em prática e trazer melhorias no processo ensino aprendizagem, tanto no contexto presencial quanto híbrido.

\section{Referências}

EXAME. Brasil é um dos países que mais usam WhatsApp, diz pesquisa. Disponível em: $<\quad$ https://exame.abril.com.br/tecnologia/brasil-e-um-dos-paises-que-mais-usamwhatsapp-diz-pesquisa/ > Acesso em 01 de maio de 20118.

GARCIA, Marilene S. S. Dossiê: EaD na escola presencial torna-se educação híbrida reflexões sobre os desafios dos professores ao articular espaços presenciais e a distância da mobilidade digital. Teccogs: Revista Digital de Tecnologias Cognitivas, TIDD | PUC-SP, São Paulo, n. 16, p. 30-37, jul-dez. 2017. Disponível em < http://www4.p ucsp.br/pos/tidd/teccogs/dossies/2017/edicao_16/teccogs16_dossie01.pdf> Acesso em 10 de maio de 2018.

GARCIA, Marilene S.S. Mobilidade tecnológica e planejamento didático. 1 ed. São Paulo: Senac, 2017.

GATTI, Bernardete A. Formação de professores no brasil: características e problemas. Educação \& Sociedade, v. 31, n. 113, p. 1356, out/dez. 2010. Disponível em: Acesso em 03 de abril de 2018.

JUBILEU, Andrea Padovan; ROCHA, Cleiton; FERREIRA, Éder. Dispositivos Móveis Visão geral (História) e tecnologia aplicada para dispositivos móveis. Instituto Federal de São Paulo - Campus Presidente Epitáfio. Disponível em: https://pep.ifsp.edu.br/moodled ata/filedir/9d/24/9d24fa21139b0d13c297cdeb083dd526930ffa15 Acesso em: 14 de maio. 2018

KENSKI, Vani Moreira. A urgência de propostas para formação de professores para todos os níveis de ensino. Revista Diálogo Educacional, v. 15, n. 45, p. 423-441, maio/ago. 2015. Disponível em: http://www.redalyc.org/html/1891/189141165004/.

MOURA, Adelina. Mobile Learning: tendências tecnológicas emergentes. Encontro sobre web 2.0, [S.L], abr. 2014. Disponível em: < file:///C:/Users/92003272/Downloads/mlearningchapterjml.pdf >. Acesso em: 17 abr. 2018.

OLIVEIRA, Estêvão Domingos Soares de; ANJOS, Eudisley Gomes dos; OLIVEIRA, 
Felipe Soares de, SOUZA, Hercilio de Medeiros;

LEITE, Jan Edson Rodrigues. Estratégias de uso do whatsapp como um ambiente virtual de aprendizagem em um curso de formação de professores e tutores. Anais do SIED: EnPED, 2014. Disponível em: Acesso em: 14 de maio. 2018

SILVA, Judith F; BATISTA, Erlinda M. Uma perspectiva de formação continuada de professores por meio da educação a distância. In ESUD - XI Congresso Brasileiro de Ensino Superior a Distância ISC, 2014. http://esud2014.nute.ufsc.br/anaisesud2014/files/pdf/128225.pdf

SOUZA, Bruno de. Mobile Learning: Educação e tecnologia na palma da mão. 1 ed. 2013, cap. 3, edição Kindle. 